\title{
AMPLIAÇÃO DO MARAVILHOSO: PEDRO PÁRAMO E CEM ANOS DE SOLIDÃO
}

Patricia Ferreira da Silva Martins*

\section{RESUMO}

Este artigo apresenta uma leitura crítico-analítica dos romances Pedro Páramo, de Juan Rulfo, e Cemı Anos de Solidão, de Gabriel Gárcia Márquez, com base na evocação do maravilhoso, conseguida através de recursos que marcam a prática literária de tais escritores.

Em meio à fertilidade produtiva da novela hispano-americana contemporânea, Pedro Páramo (1955), de Juan Rulfo, e Cem Anos de Solidão (1967), de Gabriel Garcia Márquez, se destacam como germe e flor da experiência e invenção entre tantas outras obras, sobretudo, de acordo com meu particular interesse neste trabalho, no que se refere a ampliação da literariedade de seus textos conseguida através da evocação do "maravilhoso".

O periodo temporal que separa o momento de produção destes dois romances não é grande, mas suficiente para que os recursos literários utilizados por Rulfo, em Pedro Páramo, inspirassem as inúmeras possibilidades criativas presentes em Cem Anos de Solidão. $\mathrm{O}$ caráter inovador destas duas obras é reconhecidamente significativo, ambas desafiam a percepção tradicional que sustenta as pretensões da ficção realista de reproduzir a realidade na literatura (Peck e Coyle, 1984; 1993: 130).

- Mestranda em Estudos Literários na Faculdade de Letras da Universidade Federal de Goiás (UFG) 
No presente trabalho pretendo apontar como o maravilhoso é evocado em Pedro Páramo e Cem Anos de Solidão, considerando recursos de "mitificação" da realidade e aspectos técnico-composicionais. Poderemos, assim, compreender a técnica utilizada por Juan Rulfo para atingir de modo textual os domínios do maravilhoso e como ele explora estes domínios na construção da atmosfera de seu romance e, também, como Gabriel García Márquez amplia as possibilidades de evocar o maravilhoso em Cem Anos de Solidão, através de inúmeros recursos inventivos nas mais diversas ocasiões.

Para atingir este objetivo, iniciarei com uma breve colocação sobre o que caracteriza um acontecimento como sendo "maravilhoso" de acordo com o ponto de vista estruturalista de Tzvetan Todorov. A seguir, apresentarei a contribuição surrealista para uma compreensão de maior dimensão desse artificio artístico. Apontarei, finalmente, como o maravilhoso se inscreve na realidade segundo a concepção mais recente do realismo maravilhoso, tradição a que pertencem Rulfo e Garcia Márquez. Poderei assim, simultaneamente, mostrar o desenvolvimento da definição do termo realismo maravilhoso.

O maravilhoso possui um papel definido dentro do discurso críticoliterário tradicional e, também, possui relações de caráter estrutural com o fantástico. Podemos observar minuciosamente essas relações através das colocações feitas por Tzvetan Todorov em seu livro Introdução à Literatura Fantástica $(1975 ; 1992)$. No que diz respeito a este trabalho, é de ajuda notar, apesar dos problemas na conceitualização de Todorov, uma das diferenças estruturais fundamentais entre o fantástico e o maravilhoso. $\mathrm{O}$ fantástico necessita que leitor e personagem compartilhem de uma realidade preestabelecida, de maneira que esta possa ser momentaneamente transgredida. Esta "realidade" segue a concepção realista, assim, a transgressão ocorre devido a uma ruptura com a racionalidade que, por um momento, não é suficiente para explicar objetivamente um determinado acontecimento. Já o maravilhoso, visto através desse ponto de vista estrutural, compreende a natureza de qualquer acontecimento, por mais sobrenatural que este possa parecer, como parte de uma realidade que é considerada naturalmente "mágica". Aqui, não há uma transição entre acontecimentos reais e irracionais, pois tudo é tratado em um mesmo nivel, como ocorre, por exemplo, nos contos de fada. 
A colocação de Todorov nos ajuda a começar a desenvolver nossa noção do que vem a ser o maravilhoso. Porém, para compreendê-lo na maneira em que é aplicado nos romances de Rulfo e Garcia Márquez precisaremos ir além dessa relação estrutural. Do ponto de vista surrealista, o maravilhoso está inscrito na realidade filtrando-a e transformando-a em uma outra forma de realidade, mais abrangente e sugestiva. Essa "supra-realidade" surrealista é concebida sob influência da psicanálise. De acordo com a professora Selma Calasans Rodrigues (O Fantástico, 1988, p. 57), a "supra-realidade" nasce para atender à tentativa de se expressar uma arte sem censura e sem limites para a manifestação dos desejos humanos. A partir dessa concepção, as oposições binárias, tais como realidade / irrealidade, racional / irracional, natural / sobrenatural e muitas outras, se dissolvem.

O caráter estrutural do maravilhoso é transcendido com a ajuda dessa visão surrealista da realidade, $\mathrm{e}$ isto é que transforma o maravilhoso em elemento "chave" na nova tendência hispano-americana contemporânea. A construção de uma realidade mágica na literatura possibilita a ruptura com a tradição literária realista eurocêntrica. Assim, aspectos como a estruturação narrativa, a dinâmica narracional, a mitificação da realidade e outros, são tratados de uma maneira inovadora, que marca a prática literária dos escritores hispano-americanos contemporâneos. Essa recente tendência literária, de acordo com a terminologia proposta por Irlemar Chiampi (1980), recebe o nome de realismo maravilhoso. Este termo é desenvolvido por Chiampi levando em consideração a proposta crítica do escritor cubano Alejo Carpentier, que utiliza o termo real maravilhoso numa tentativa de designar, de uma só vez, a realidade do homem americamo e a maneira "mágica" com que essa realidade é absorvida pelo europeu. Chiampi, por sua vez, considerara as colocações de Carpentier, mas situa a tendência hispano-americana contemporânea de uma maneira mais formal, com base nas caracteristicas do discurso dessa tendência e não na maneira de se perceber a realidade:

Ao contrário da "poética da incerteza," calculada para obter o estranhamento do leitor, o realismo maravilhoso desaloja qualquer efeito emotivo de calafrio, medo ou terror sobre o evento insólito. No seu lugar, coloca o encantamento como um efeito discursivo pertinente à interpretação não-antitética dos componentes diegéticos. O insólito, 
em óptica racional, deixa de ser o "outro lado," o desconhecido, para incorporar-se ao real: a maravilha é(está) (n)a realidade. Os objetos, seres ou eventos que no fantástico exigem a projeção lúdica de duas probabilidades externas e inatingiveis de explicação, são no realismo maravilhoso destituidos de mistério, não duvidamos quanto ao universo de sentido a que pertencem.'

A definição de Chiampi nos ajuda a ter uma maior compreensão da importância do maravilhoso para a literatura hispano-americana recente. A visão da realidade como sendo maravilhosa por sua própria natureza, com seus mitos e lendas, gente e vida cotidiana colabora com a elaboração de Pedro Páramo e Cem Anos de Solidão. Nestas obras há a rejeição da oposição entre natural e sobrenatural. Em Pedro Páramo, por exemplo, Juan Preciado, assim como o leitor, encontra a razão para a sua morte nos sussurros: "- Sim Dorotea. Os sussurros me mataram" (p. 52). A possibilidade de uma vida dentro de uma realidade sobrenatural não é nunca questionada e o leitor não é instigado a decifrar a natureza dos acontecimentos.

Juan Rulfo faz uso de uma técnica objetiva com a intenção de evidenciar ainda mais o que existe de subjetivo no mundo. Sua linguagem pode ser considerada tão concreta quanto a de um escritor "realista", no entanto, o resultado alcançado por Rulfo é o da "supra-realidade" que nos coloca no âmbito do maravilhoso. É interessante notarmos aqui que, a fidelidade a realidade concreta resulta em um "salto" ainda mais profundo para dentro do mundo subjetivo.

A penetração na esfera do maravilhoso é alcançada por Rulfo através da objetividade técnica, sendo esta, a meu ver, uma das grandes renovações artísticas deste escritor. A estruturação de Pedro Páramo é organizada através da rememoração. $\mathrm{O}$ desenrolar dos acontecimentos está sujeito ao poder de reanimação das lembranças permitido pelo ato de recordar que, em Pedro Páramo, graças ao recurso do maravilhoso, nem mesmo a morte pode interromper. Esta é uma estrutura que evoca o eterno retorno da concepção cíclica do mito. Logo no início da novela, Juan Preciado chega a Comala à procura de seu pai, Pedro Páramo, em cumprimento a uma promessa feita à mãe em seu leito de morte: "Vim a Comala porque me disseram que aqui vivia meu pai, um tal de Pedro Pára- 
mo. Minha mãe que disse. E eu prometi que viria vê-lo quando ela morresse." (Pedro Páramo, p. 9)

A penetração de Juan Preciado no espaço esquecido de Comala na procura do pai, possui um caráter mítico. $\mathrm{O}$ componente mítico fornece uma característica "universal" ao romance, pois não está centrado no sujeito individual, mas sim num código universal (mito) capaz de revelar sua lógica própria. Segundo Florence Leaver (Kulin, 1980, p. 103) : "Primitive or literary, a myth is created by, and in turn creates, a sense of wonder, a sense of the marvellous." Acredito que seja assim que as dimensões do mito e do maravilhoso se confundem numa relação dialética, pois em alguns momentos não veremos nenhuma distinção entre eles apesar de terem seus limites definidos separadamente.

Em Pedro Páramo as origens do "Mito do Eterno Retorno" são reconstruidas por Juan Rulfo. Um fundamento básico para o eterno retorno se encontra numa simbólica transformação transcendental do centro cósmico. Este centro, segundo Mircea Eliade (em Álvarez, 1983, p. 29), pode estar constituido de um templo ou uma cidade: "Being an axis mun$d i$, the sacred city or temple is regarded as the meeting point of haven, earth, and hell." Desde as primeiras páginas do romance de Rulfo, podemos reconhecer o papel de Comala como axis mundi, onde terra e inferno se confundem: "Aquilo [Comala] está sobre as brasas da terra, na própria boca do inferno." (Pedro Páramo, p. 11)

A morte de Juan Preciado me parece fazer ressaltar ainda mais o poder do maravilhoso de evocar interpretações com sentidos mais profundos. A intensidade dos sentimentos dos personagens se faz mais perceptivel por serem capazes de transcender a própria vida: "Lá você vai me ouvir melhor. Estarei mais perto. Vai achar a voz das minhas recordações mais próxima que a da minha morte, se é que algum dia a morte teve voz" (p. 13).

Após a morte de Preciado, os narradores da novela passam a ser os fantasmas que, ao se agarrarem à suas "vidas incompletas", nos fazem interpretar suas ações e pensamentos com uma perspectiva não convencional - pois não temos, dentro do nosso código moral preestabelecido, normas para aplicarmos a tal circunstância. Rulfo recria em Comala um mundo que foge dos limites da realidade objetiva, o que demanda um 
cuidadoso exercício de leitura: "La compreesión de una realidad tan inusitada exige una lectura más cercana a la poesía que a la prosa de ficción." É através da evocação do maravilhoso que Juan Rulfo constrói a atmosfera de Pedro Páramo. Ao apresentar a pequeníssima Comala onde Juan Preciado é sufocado por um calor opressivo, Rulfo faz com que a realidade exterior se converta, também, em realidade interior. Para Katalin Kulin, em obra já citada, essa sensação extremamente real de calor e sufocamento cria "maravilhosamente" um espaço fora da realidade imediata: "Não havia ar. Tive que aspirar o mesmo ar que saia da minha boca, retendo-o com as mãos antes que fosse embora. Sentia-o ir e vir, cada vez menos; até que ficou tão fino que escoou por entre os meus dedos para sempre" (p. 51).

Vemos assim a introdução de um recurso transgressor que abala as formas superficiais do realismo stricto sensu. A sensação do maravilhoso é evocada pelas ilusões alucinantes que funcionam como um reflexo da realidade circundante. Essa atmosfera "maravilhosa" criada por Rulfo nos mostra o poder do maravilhoso em fazer com que o caráter mais enigmático da vida possa ser apreendido pelo leitor. É essa força maravilhosa que faz, também, com que os mortos de Comala insistam em seguir "vivendo" mesmo aprisionados num mundo infernal e infindável:

A única coisa que faz a gente mover os pés é a esperança de que ao morrer levem a gente de um lugar para o outro; mas quando fecham uma porta pra gente e a que fica aberta é só a do inferno, seria melhor nem ter nascido...Para mim, Juan Preciado, o céu está aqui onde eu estou agora. (p. 57)

Gabriel Garcia Márquez multiplica as possibilidades de evocar o maravilhoso em Cem Anos de Solidão, sem que para isso tenha que desenvolver uma complicada técnica narrativa. Pelo contrário, seu romance é fundamentalmente diferente justamente por ser puramente espontâneo e de fácil acesso para o leitor, como observa John Brushwood (conforme citado em artigo de Levitt):

It is a very strange reality, but it is entirely accessible to the reader since there are no barriers created by difficult narrative techniques....He seems to write from inspiration, using what he remembers 
combined with what he thinks of during the process of writing. His novel has a high level of spontaneity; it does not have a carefully worked pattern of meaning. ${ }^{3}$

O cenário de Cem Anos de Solidão também é constituido por um pequeno povoado perdido no tempo e no espaço. Macondo, assim como Comala, exala uma sensação de sufocamento e isolamento paralisantes. A natureza envolve Macondo em uma espécie de barreira vegetal, o que reforça maravilhosamente seu ambiente de paralisia:

Ao sul estavam os charcos cobertos de uma eterna nata vegetal, e o vasto universo do grande pantanal, que, segundo testemunho dos ciganos, carecia de limites. (p. 16).

[Ao norte] O solo tornou-se mole e úmido, como cinza vulcânica, e a vegetação fez-se cada vez mais insidiosa, e ficaram cada vez mais longinquos os gritos dos pássaros e a algazarra dos macacos, e o mundo ficou triste para sempre. (p. 17)

O espaço e o tempo nos mitos não conduzem a novas experiências, por terem em sua base a totalidade a priori do mundo. $\mathrm{O}$ caráter mítico de Cem Anos de Solidão começa aqui, o eterno retorno, que constitui a fórmula cíclica dos mitos, está também presente nesta obra. $\mathrm{O}$ incesto que deu origem à familia Buendia e o nascimento do monstro com rabo de porco se repete ao final da narrativa conferindo-lhe a circularidade que a aproxima da completude mítica:

Depois de cortar o umbigo, a parteira pôs-se a remover com um trapo o ungüento azul que the cobria o corpo, iluminada por Aureliano com uma lâmpada. Só quando viram de costas é que perceberam que ele tinha alguma coisa a mais que o resto dos homens e se inclinaram para examiná-lo. Era um rabo de porco. (p. 390)

$\mathrm{O}$ mito do eterno retorno é apenas um entre vários mitos de que García Márquez se utiliza e/ou re-elabora na evocação do maravilhoso em Cem Anos de Solidão:

Cien años de soledad tells a story of foundations or origins, the whole novel has a mythic air about it. No single myth or mythology prevails. Instead the various ways in which myth appears give the whole novel a mythical character without it being a distinct version of one given myth. ${ }^{4}$ 
O destino já "escrito" dos Buendias os obriga a viver uma vida de alienação e paralisia. Esse destino preestabelecido é aos poucos revelado ao leitor no decorrer da narrativa através de premonições, adivinhações, e pressentimentos que, a todo momento, evocam a realidade maravilhosa do romance. As cartas de Pilar Ternera revelam parte destes destinos, mas existem também outros tipos de revelações ainda mais enigmáticas, como as borboletas que envolvem Meme e Maurício Babilônia: "As borboletas invadiam a casa desde o entardecer. Todas as noites, ao sair do banheiro, Meme encontrava Fernanda desesperada, matando borboletas com a bomba de inseticida" (Cem Anos de Solidão, p. 278); ou o caso dos pássaros que Amaranta Úrsula traz consigo em enormes gaiolas que partem assim que são libertados, prenunciando o exterminio total dos Buendia: "Ả medida que os pássaros se reproduziam, Amaranta Úrsula os ia soltando aos casais, e demoravam mais para se sentir livres do que para fugir do povoado" (p. 358 - 359).

Através do recurso do maravilhoso, Rulfo e Garcia Márquez fazem manifestar o caráter mítico de seus personagens, o qual é marcado por suas condições humanas. Para Rulfo essa condição é a força interior ilimitada de seus personagens, García Márquez, por outro lado, encontra essa condição na incapacidade de amar. Os personagens de Cem Anos de Solidão são, aparentemente, revestidos pelo desamor, que os ajuda a resistir à eterna solidão.

Podemos encontrar em cada personagem de Cem Anos de Solidão a figura de um herói mítico. Para converter seus personagens nesses heróis, García Márquez lança mão, muitas vezes, de motivos miticos bíblicos e clássicos, que também funcionam como artificios para a manifestação do maravilhoso, como por exemplo, o caso de José Arcadio Buendía que, amarrado ao castanheiro do pátio, evoca o destino de Prometeu; o hábito do Coronel Aureliano Buendía de fazer e desfazer peixinhos de ouro, o que nos remete à figura de Penelope; a ascensão aos céus de Remédios a bela sugere a ascensão da virgem.

O maravilhoso, também, é sugerido por Garcia Márquez através do exagero. Todos os personagens de Cem Anos de Solidão possuem características extrapolantes em algum sentido. José Arcádio Buendia, Úrsula, Melquiades e Pilar Ternera têm vidas extremamente longas (o que 
também pode remeter aos mitos bíblicos); Rebeca, Meme, Amaranta e Amaranta Úrsula vivem paixões sem limites; Remedios a bela é inconcebivelmente bela e desprendida de qualquer tipo de convenção. $\mathrm{O}$ escritor se utiliza de todos esses recursos da maneira mais natural possivel, como se estivesse retratando os membros ordinários de qualquer comunidade.

García Márquez entende o maravilhoso como sendo algo essencial ao ser. Ele parece evocar o maravilhoso para interpretar os enigmas que estão fora do nosso conhecimento. Segundo suas próprias declarações, o escritor encaixa os acontecimentos inverossimeis para fazê-los aceitos pelo leitor em circunstancias cotidianas. É dessa maneira que Remedios a bela ascende aos céus com os lençóis de Fernanda:

Fernanda sentiu que um delicado vento de luz lhe arrancava os lençóis das mãos e os estendia em toda a sua plenitude. Amaranta sentiu um tremor misterioso nas rendas das suas anáguas e tratou de se agarrar no lençol para não cair, no momento em que Remedios a bela, começava a ascender. (p. 228).

Garcia Márquez se utiliza de tal recurso artístico (o inverossímil dentro das circunstâncias cotidianas), para mostrar enfaticamente que o maravilhoso está profundamente arraigado à nossa realidade. É assim também que o escritor usa o engraçado e/ou irônico à serviço do maravilhoso. É o que ocorre no caso da levitação do Padre Nicanor Reyna com a ajuda de uma caneca de chocolate - "prova irrefutável do infinito poder de Deus" (p. 84). Essa força maravilhosa que faz com que o Padre Nicanor Reyna possa levitar, é uma força natural que está contida em cada personagem de Cem Anos de Solidão. É por isso que caem flores amarelas do céu quando morre José Arcádio Buendia: "Pouco depois, quando o carpinteiro tomava as medidas para o ataúde, viram pela janela que estava caindo uma chuvinha de minúsculas flores amarelas" (p. 138).

Como alguns críticos já observaram, nós podemos entender o universo que Garcia Márquez cria em Cem Anos de Solidão, como sendo um organismo vivo que, de uma maneira maravilhosa, tem o poder de reagir a tudo o que afeta seus personagens. Tudo o que se passa de "irreal" parece estar mais ainda integrado ao mundo natural. Assim, o maravilho- 
so é levado aos extremos que o poder de criação de Garcia Márquez pode conceber. Como tudo é muitíssimo harmonioso, em Cem Anos de Solidão, quase não há a necessidade de explicações. Quando alguma explicação aparece, vem de dentro da própria comunidade, sem a interferência de um narrador onisciente. No caso do galeão espanhol não há nenhuma explicação sobre sua procedência, somente o que ele evoca em seus observadores é que tem importância, que é a possibilidade de uma realidade diferente, num universo sem tempo e sem espaço: "Toda a estrutura parecia ocupar um âmbito próprio, um espaço de solidão e esquecimento, vedado aos vícios do tempo e aos maus hábitos dos pássaros" (p. 17).

As explicações saidas do interior da comunidade também funcionam como afirmações de uma realidade maravilhosa, pela maneira como invertem o sentido da realidade propriamente dita. É como se houvesse uma inversão na relação entre causa e efeito no nivel do raciocínio dos personagens. Lembrando aqui, que esta é uma situação diferente da ausência da relação entre causa e efeito que aparece em Pedro Páramo no nivel das ações, onde uma personagem já morta, como Damiana Cisneros, reaparece para cuidar de Pedro Páramo.

Esse processo de inversão faz com que as pessoas em Macondo queiram dormir durante a doença da insônia "não por cansaço, mas por saudades dos sonhos" (p. 49). Isto ocorre em várias ocasiões, com a ajuda do recurso retórico "não por... mas por..." e/ou "não porque... mas sim porque...", onde uma conclusão obvia é substituida por algo secundário. Algo semelhante utilizado no maravilhoso de Garcia Márques é o deslocamento do essencial para o periférico, é através desse recurso que os habitantes de Macondo não se revoltam com a fraude e a corrupção na eleição, mas sim com o fato dos soldados terem confiscado suas facas de cozinha: "O que na verdade causou indignação no povoado não foi o resultado das eleições, mas o fato dos soldados não lhes terem devolvido as armas." (p. 97).

Gabriel García Márquez explora de inúmeras maneiras as possibilidades de evocar o maravilhoso em Cem Anos de Solidão. Rulfo se utiliza deste elemento para construir a atmosfera maravilhosa de Pedro Páramo. Acima de tudo, eles nos mostram através de suas técnicas um caminho para a exploração de uma realidade textual mais complexa. O maravilho- 
so, evocado pelos recursos inovadores que marcam a prática literária hispano-americana contemporânea, delega força politica a tais obras, possibilitando a ruptura com a cultura tradicional eurocêntrica e permitindo a expressão da experiência autônoma da América hispânica.

Devemos, assim, nos lembrar que o maravilhoso não é apenas um artificio artístico presente em Pedro Páramo e Cem Anos de Solidão, ele compõe a própria essência das obras hispano-americanas contemporâneas. A utilização do maravilhoso, de acordo com essa tendência, não apenas altera nosso paradigma de leitura, mas também amplia nosso senso criti$\mathrm{co}$, de forma a rejeitarmos, como leitores e como pessoas, julgamentos críticos precstabelecidos.

\footnotetext{
ABSTRACT

This article presents a critical reading of the novels Pedro Páramo, by Juan Rulfo, and One Hundred Years of Solitude, by Gabriel Gárcia Márquez, based on the evocation of the "Marvellous", achieved through the use of devices which mark the literary practice of these writers.
}

\section{NOTAS}

1. CHIAMPI, I. O Realismo Maravilhoso. São Paulo: Perspectiva, 1980 , p. 50.

2. BRUSHWOOD, J. A. La Novela Hispano-americana del Siglo XX. Una Vista Panoramica. México: Fondo de Cultura Económica, 1984, p. 192.

3. LEVITT, M. P. From Realism to magic realism: The Meticulous Modernist Fictions of Gabriel Garcia Márquez. In: Bloom, H. (editor). Modern Critical Views, Gabriel Garcia Márquez. Philadelphia: Chelsea House, 1989, p. 227-228.

4. ECHEVARRIA, R. G. Cien Años de Soledad: The Novel as Myth and Archive. In: BLOOM, H. (editor), op. cit., p. 114. 


\section{REFERÊNCIAS BIBLIOGRÁFICAS}

ÁlVAREZ, N. E. Análisis Arquetipico Mitico y Simbológico de Pedro Páramo. Miami: Ediciones Universal, 1983.

BÁEZ, Y. J. Juan Rulfo, del Páramo a la Esperanza, una Lectura Critica de su Obra. México: Fondo de Cultura Económica, 1990.

BLOOM, H. (ed). Modern Critical Views, Gabriel Garcia Márquez. Philadelphia: Chelsea House, 1989.

BOECHATT, W. (org). Mitos e Arquétipos do Homem Contemporâneo. Petrópolis: Vozes, 1995.

BRUSHWOOD, J. S. La Novela Hispano-Americana del Siglo XX, una Vista Panoramica. México: Fondo de Cultura Económica, 1984.

CHIAMPI, I. O Realismo Maravilhoso. São Paulo: Perspectiva, 1980.

JOSEF, B. Romance Hispano-Americano. São Paulo: Ática, 1986.

KLALIN, N. e CORRAL, W. Los Novelistas como Criticos. México: Fondo de Cultura Económica, 1991.

KULIN, K. Creación Mitica en la Obra de Garcia Márquez. Budapest: Akadémiai Kiadó, 1980.

MÁRQUEZ, G. G. Cem Anos de Solidão. Rio de Janeiro: Record, 1995. PECK, J. e COYLE, M. Literary Terms and Criticism. London: Macmillan, 1993.

RODRIGUES, S. C. O Fantástico. São Paulo: Ática, 1988.

RULFO, J. Pedro Páramo e o Planalto em Chamas. São Paulo: Paz e Terra, 1986.

TODOROV, T. Introdução à Literatura Fantástica. São Paulo: Perspectiva, 1992. 